\title{
Crimes de imprensa nos tribunais paulistas (1859-1935)
}

\section{Press Crimes in São Paulo's Courts of Justice (1859-1935)}

\section{Rodrigo Camargo de GODOI*}

Resumo Durante cerca de cem anos, ou seja, entre a promulgação do Código Criminal de 1830 e do Decreto n. 24.776 de 14 de julho de 1934, os Autos Crimes de Exibição de Autógrafo atuaram como ações preparatórias que antecediam a instauração de processos de injúria e calúnia impressas. Por conseguinte, baseando-se em uma série desses processos criminais julgados nas Comarcas de Campinas e Bragança, entre 1859 e 1935, este artigo analisa os efeitos da expansão da malha tipográfica pelo interior de São Paulo, atento às transformações impostas pela chegada de prelos e jornais. Com efeito, além de uma reflexão sobre as práticas de leitura em sociedades marcadas por índices de analfabetismo significativos, a pesquisa investiga os imbricamentos entre cultura impressa e cultura jurídica no Brasil no momento em que os novos regimes constitucionais do século XIX tiveram que lidar com o controle e regulamentação legal da produção e circulação de impressos. Palavras-chave imprensa, direito, crimes de imprensa

\footnotetext{
* https://orcid.org/0000-0001-7570-8503

Universidade Estadual de Campinas, Departamento de História Rua Cora Coralina, 100, 13083-896, Campinas, São Paulo, Brasil rcgodoi@unicamp.br
} 
Abstract For about a century, between the enactment of the Criminal Code in 1830 and the Decree no. 24,776 of July 14, 1934, the Lawsuits of Autographs' were preparatory lawsuits that preceded the filing of libel and slander court cases. Consequently, based on a series of these proceedings judged in the counties of Campinas and Bragança, between 1859 and 1935, this article analyzes the impact of the expansion of the typographic mesh in São Paulo's state countryside, attentive to the transformations imposed by the arrival of presses and newspapers in the daily lives of men and women alike. Therefore, in addition to analyzing the reading practices in societies marked by significant illiteracy rates, the research investigates the nexus between print and legal culture in Brazil at a time when the new constitutional regimes of the 19th century had to deal with the control and legal regulation of print production and circulation.

KEYWORDS press, law, press crimes

\section{INTRODUÇÃO}

Extremamente importantes aos novos regimes constitucionais de fins do século XVIII e início do século XIX, as diferentes modalidades de liberdade de expressão encontrariam uma primeira formulação e defesa consistentes no Aeropagítica de John Milton, publicado no esteio da Reforma e das revoluções tipográfica e inglesa, em 1644 (MILTON, 1999; SEELANDER, 1991). Desse ponto em diante da história, a garantia da liberdade de comunicar os pensamentos se converteria em um axioma do pensamento liberal que esteve na base do movimento constitucionalista emergido do colapso do Antigo Regime. Nesse sentido, a Constituição do Império do Brasil (1824), outorgada por d. Pedro I, assegurava-a aos cidadãos brasileiros nos seguintes termos:

[Art. 179] IV. Todos podem comunicar os seus pensamentos, por palavras, escritos, e publica-los pela Imprensa, sem dependência de censura; com tanto que hajam de responder 
pelos abusos, que cometerem no exercício deste Direito, nos casos, e pela forma, que a Lei determinar. ${ }^{1}$

A partir de 1830, com a promulgação do Código Criminal do Império, assim como outras leis e decretos, a liberdade de expressão foi sendo regulada de modo mais preciso no Brasil. Ao examinarmos brevemente o Código Criminal (1830), salta aos olhos a preocupação dos legisladores com a dimensão político-teológica dos crimes dessa natureza. Assim, era considerado delito grave atentar, por intermédio de "papéis impressos, litografados ou gravados, que se distribuírem por mais de quinze pessoas", contra a integridade e independência do Império, sua Constituição e seu monarca; zombar do catolicismo, a religião oficial do Estado, ou lançar suspeitas da existência de Deus e da imortalidade da alma.

Pouco atenta aos elementos religiosos, boa parte da historiografia tem enfatizado os aspectos políticos da liberdade de imprensa no século XIX. Ao estudar o caso mexicano, Fausta Gantús defende que "a regulação e controle da imprensa são ferramentas privilegiadas para atuar na política. As discussões sobre o tema se projetam no tempo marcando períodos de grande agitação política na esfera pública" (GANTÚS, 2019, p. 94-95). Para a historiadora, as liberdades de imprensa e expressão seriam fatores capitais à vida política no contexto de formação e consolidação dos Estados nacionais na América Latina. No entanto, Gantús defende que se tais liberdades estiveram na base dos sistemas republicanos e liberais que emergiram no continente, elas também foram consideradas elementos de perturbação e dissolução dos sistemas que as engendravam. Portanto, uma faca de dois gumes que podia ser ostentada como emblema do avanço das liberdades políticas e, há um só tempo, fator de desestabilização política (GANTÚS, 2019).

1 BRAZIL. Constituição Politica do Imperio do Brazil (1824). Carta de Lei de 25 de março de 1824. Leis, Alvarás e Cartas Imperiaes. Rio de Janeiro: Secretaria de Estado dos Negocios da Justiça, 1824. Disponível em: < http://www. planalto.gov.br/ccivil_03/Constituicao/Constituicao24.htm >. Acesso em: 27 set. 2019.

2 BRAZIL. Código Criminal do Imperio do Brazil. Lei de 16 de dezembro de 1830. Rio de Janeiro: Secretaria de Estado dos Negocios da Justiça, 1831. Disponível em: < http://www.planalto.gov. br/ccivil_03/leis/lim/LIM-16-12-1830.htm >. Acesso em: 11 dez. 2019. 
O caso mexicano é igualmente objeto das análises de Corinna Zeltsman (2018). Ao estudar a trajetória do impressor Ignácio Cumplido na Cidade do México nos anos 1840, a historiadora tem questionado as interpretações de cunho habermasiano que consideram a imprensa em termos abstratos, enquanto elemento fundante das esferas públicas durante e depois das independências na América Latina. Para Zeltsman, deve-se analisar a imprensa em seu contexto material, político e social, considerando especialmente os processos de produção e consumo dos impressos. Com efeito, as disputas sobre a definição das reponsabilidades jurídicas de impressores e editores mexicanos estiveram no centro da constituição da liberdade de imprensa naquele país.

De modo semelhante, os Autos Crimes de Exibição de Autógrafos julgados nos tribunais paulistas revelam de um ângulo diverso os mecanismos pelos quais a liberdade de imprensa foi constituída em meio a embates sociais e jurídicos envolvendo redatores, proprietários de jornais, impressores, jornalistas e leitores no Brasil por aproximadamente um século, de Feijó a Vargas. Por conseguinte, a análise dessa documentação, ainda pouco explorada pela pesquisa histórica, pode-nos auxiliar na construção de uma história social e cultural da liberdade de imprensa e das práticas de leitura no Brasil.

\section{IMPRENSA E COTIDIANO EM SÃo PAUlo}

Os discursos e relatórios dos presidentes da Província de São Paulo, apresentados à Assembleia Legislativa Provincial no início da década de 1840, bem documentam as dificuldades enfrentadas pela tipografia do governo. No discurso proferido em janeiro de 1841, Rafael Tobias de Aguiar narrava aos deputados o desinteresse por parte de tipógrafos e impressores de São Paulo no arrendamento da oficina tipográfica provincial. Aguiar argumentava principalmente sobre o papel desempenhado pela imprensa nos regimes constitucionais e parlamentares que, no caso brasileiro, ganhavam contornos cada vez mais nítidos precisamente naquele momento: 
Vós conheceis a necessidade de publicarem-se os atos do Governo e de outras repartições públicas: é esta uma das condições do sistema representativo. A publicidade é nos governos constitucionais o mais poderoso corretivo dos abusos dos governantes, e só a temem aqueles que não se animam a expor às vistas do público o seu comportamento na direção dos negócios, em que o mesmo público tem o maior e mais particular interesse (DISCURSO, 1841, p. 7).

O problema em breve seria sanado na medida em que a Tipografia do Governo já estava a cargo de Silva Sobral, em 1843. Na década seguinte, ela seria novamente arrendada, desta vez a Antonio Louzada Antunes, impressor que acabou por comprá-la, em 1854 (DISCURSO, 1843; RELATÓRIO, 1854, p. 39). Não obstante os tropeços enfrentados pela tipografia oficial da Província que culminaram na sua privatização, para empregarmos vocabulário hodierno, desde 1827, ano do início da publicação do Farol Paulistano, as oficinas tipográficas e os jornais aumentavam exponencialmente na cidade e Província de São Paulo (FREITAS, 1928, p. 7-42).

Ao estabelecer uma divisão cronológica para o Segundo Reinado, Joaquim Nabuco identificou precisamente no período entre 1871 e 1878 o "começo da democratização do sistema", associando-o à "imprensa e conduções baratas". O aumento do número de "bonds" e a proliferação de jornais e periódicos, para todos os gostos e bolsos, revolucionavam “antigos hábitos da população" (NABUCO, 1897, p. 553). No limite, para Marie-Eve Thérenty, esse movimento daria ensejo à inauguração de uma nova relação dos indivíduos com o tempo no oitocentos, relação essa baseada no regime de periodicidade característico da imprensa. "Durante o século XIX", nas palavras da historiadora, "o conjunto da sociedade obedece de maneira cada vez mais acentuada ao paradigma da periodicidade" (THÉRENTY, 2013, p. 52-53).

No que diz respeito ao interior da Província, que particularmente nos interessa, um levantado realizado a partir de Almanaques de São Paulo publicados na segunda metade do século XIX, sugere que a década de 
1870 fora, de fato, determinante para a expansão da malha tipográfica para além da capital. Os dados também apontam que, em certas localidades, tal expansão pode ter precedido as ferrovias. Logo, em um exercício de imaginação histórica, podemos visualizar prelos, barris de tinta, resmas de papel e toda sorte de material tipográfico sendo transportados em lombos de mulas interior adentro. Duas cidades se destacariam nesse cenário: Santos, obviamente favorecida pelo porto que dispensaria as mulas, e Campinas, para a qual, até certa altura do oitocentos, as mulas seriam imprescindíveis. Elaborado a partir dos Almanaques publicados em São Paulo em 1873, 1884 e 1896 (LUNÉ; FONSECA, 1873; MOURA, 1883, p. 346-347; ALMANACH, 1896), o Mapa 1 indica que, irradiando-se a partir da capital, a expansão da malha tipográfica pelo interior da província seguiu o leito do Rio Paraíba em direção ao Rio de Janeiro, tomando em seguida os rumos do Oeste Paulista e demais regiões. Portanto, não seria descabido afirmar que, em São Paulo, as tipografias floresceram à sombra das centenas de milhares de pés de café que, desde meados do século XIX, geravam a riqueza da região.

Figura 1: Expansão da malha tipográfica pelo interior de São Paulo

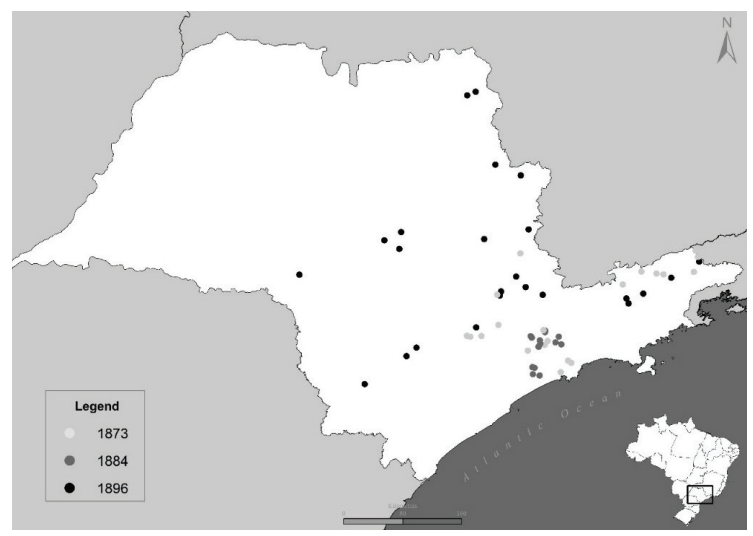

Fonte: PIRES, Tiago; GODOI, Rodrigo Camargo de. Expansão da malha tipográfica pelo interior de São Paulo. Mapa, 2019.3

3 Baseado em dados por mim coletados durante a pesquisa, o mapa foi elaborado e gentilmente cedido pelo geógrafo Tiago Pires, a quem agradeço. 
Conforme revelado pelo Censo de 1872, também não seria prudente desconsiderar o baixo índice de letramento verificado entre os paulistas, livres e cativos. Antes, seria válido questionar em que medida o analfabetismo generalizado poderia ter impactado a indústria gráfica em São Paulo. Todavia, o fato de 79,3\% dos habitantes livres da Província serem analfabetos não intimidou tipógrafos, impressores e redatores. Bragança, nesse sentido, pode ilustrar bem esse quadro. De acordo com os dados do Censo de 1872, as taxas de alfabetização na localidade também não eram promissoras. Localizado a poucas léguas da capital, $\mathrm{o}$ município possuía ao todo 19.495 habitantes, dos quais $87 \%$ eram livres e $13 \%$ cativos. Entre a população livre de Bragança destacam-se os pardos (29,9\%), pretos $(11,7 \%)$ e caboclos $(9,4 \%)$. Ou seja, os brancos restringiam-se a $48,8 \%$ da população livre lá residente. Em relação às taxas de letramento, não havia indícios de escravos alfabetizados em 1872, sendo que apenas 9,3\% da população livre sabia ler e escrever - percentual que, em números absolutos, representava 1.161 homens e 437 mulheres. ${ }^{4}$

A despeito da escassez de gente letrada, um levantamento publicado em fins do século XIX evidencia que 23 periódicos foram publicados na cidade entre 1875 e 1895. Seguindo uma tendência do jornalismo oitocentista brasileiro, alguns desses jornais e revistas não sobreviveram sequer ao primeiro número, a exemplo de Picapau (1876), Rabiscos (1890), O Abutre (1892) e o Vampiro (1892). No entanto, encontramos em Bragança jornais com relativa longevidade, como O Guaripocaba, que circulou entre 1877 e 1888, sendo posteriormente transformado no Diário de Bragança (LAPA, s. d., p. 237-239).

Entretanto, as cifras da expansão da malha tipográfica pelo interior de São Paulo mostram apenas uma face da questão. Tabelas e números não nos permitem acessar os modos pelos quais a imprensa alterou o cotidiano de homens e mulheres, livres e cativos, em cidades como Bragança e Campinas no século XIX. Nesse ponto, a documentação

4 Dados do Censo de 1872 podem ser consultados em: Pop 1872 - Brasil. Recenseamento do Império do Brasil. In: Núcleo de Pesquisa em História Econômica e Demográfica. Disponível em: < http://www.nphed.cedeplar.ufmg.br/pop-72-brasil/ > . Acesso em: 28 set. 2019. 
judicial é bastante útil. Os Autos Crimes de Exibição de Autógrafo julgados nas Comarcas de Campinas e Bragança revelam aspectos inéditos do imbricamento entre imprensa, sociedade e justiça entre meados do século XIX e as primeiras décadas do século XX. Mas se, desde o Império, o arcabouço legal que regulou a impressa preocupou-se primordialmente com os crimes de sedição, no dia-a-dia de sociedades expostas às novas tecnologias de impressão eram as injúrias e calúnias que levavam impressos e pessoas aos tribunais.

\section{Autos CRIMES DE EXIBIÇÃo DE AUTÓGRAFO NAS COMARCAS DE BRAganÇA E CAMPINAS}

Os Autos Crimes de Exibição de Autografo eram ações preparatórias que antecediam a instauração de processos de injúria e calúnia impressas. Embora a investigação ainda necessite avançar de modo mais sistemático em direção à legislação de imprensa, uma leitura da série dos 48 processos até aqui localizados revela que o arcabouço jurídico que os regulava vigorou, com poucas variações, por cerca de cem anos. Ou seja, da promulgação do Código Criminal de 1830 e, sobretudo, do Decreto de 18 de Março de 1837, que instruía sobre o andamento dos processos e sentenças nos casos de crimes de imprensa, até o Decreto n. 24.776, de 14 de julho de 1934, que reiterou a proibição do anonimato já vetado na Constituição republicana de 1891, autorizando-o apenas nos casos de "segredo de redação" restritos à imprensa política e noticiosa. ${ }^{5}$

Em linhas gerais, os processos eram instaurados quanto um indivíduo, sentindo-se injuriado por determinado escrito publicado na imprensa, acionava a justiça para que o proprietário, redator ou editor do jornal ou periódico apresentasse perante o Juiz de Direito o manuscrito

5 O primeiro processo a citar o Decreto de 18 de março de 1837, data de 1881: CMU TRIBUNAL DE JUSTIÇA DE CAMPINAS, Campinas. NAVARRO, João Gabriel M. Exibição de autógrafo. Réu: Gazeta de Campinas, 1881. Ofício 2, cx. 46, n. 498. O Decreto n. 24.776 de 14 de julho de 1934, por sua vez, foi citado em 1935: CMU TRIBUNAL DE JUSTIÇA DE CAMPINAS, Campinas. PIRES NETO, José. Exibição de autógrafo. Réu: Diário do Povo, 1935. Ofício 3, cx. 50, n. 724 . 
original acompanhado do autógrafo e documento de reponsabilidade de seu autor ou responsável legal. Invariavelmente, um exemplar do impresso era dobrado e anexado ao processo com o artigo reputado injurioso tarjado com lápis colorido. Finda a audiência e identificada a autoria ou a responsabilidade, uma vez que o autor não necessariamente podia ser o responsável legal pelo artigo, os autos permaneciam à disposição das partes para que os advogados dos injuriados pudessem proceder com uma queixa crime que, por sua vez, originaria um novo processo. Em artigo publicado na Gazeta Jurídica, em 1875, Saldanha Marinho advertia sobre o emprego de laranjas neste tipo de ação: "Artigos publicados na imprensa, com assinatura de seus autores, têm sido chamado a juízo e aí aparece um testa de ferro que toma a si a responsabilidade; só contra este se procede criminalmente" (MARINHO, 1875, p. 464-481).

Embora ainda não tenha localizado a segunda etapa dos processos, a primeira é muito importante, pois os Autos Crimes de Exibição de Autógrafo solucionavam um problema legal imposto pelo sistema de responsabilidade sucessiva adotado no Brasil desde os tempos de d. João VI. Instituído em 1821, esse sistema de culpabilidade determinava que os responsáveis nos casos de crime de imprensa seriam, em primeiro lugar, os autores seguidos dos editores ou proprietários de jornais e revistas; em terceiro lugar, os impressores e, por fim, os livreiros. $\mathrm{Na}$ medida em que o anonimato do autor havia sido garantido por lei, ao passo que a identificação do editor, redator-chefe ou proprietário de uma editora, jornal ou periódico tornara-se compulsória, eram os últimos os primeiros a serem acionados na justiça em caso de publicações consideradas sediciosas, imorais ou injuriosas. Por um século, ao menos do ponto de vista jurídico, foi mais arriscado imprimir e editar do que escrever no Brasil (GODOI, 2016, p. 97-112).

Os nexos do sistema de responsabilidade sucessiva e da exibição de autógrafo em juízo ficam mais claros ao acompanharmos, por exemplo, a indignação de Antonio Rodrigues Barbosa diante do Diário de Campinas de 19 de julho de 1876. Lendo os “Comunicados", seção paga daquele jornal, eis que o Sr. Antonio se deparou com uma nota intitulada "Misericórdia!...": 
Misericórdia!...

Onde se viu um marido deixar que a mulher deite pela porte fora sua mãe (cega) e seu pai aleijado de um braço?

É a última expressão de crueldade!

As tais biscas mereciam ter a figura de tigres, ou então como moram na rua da Cadeia e estão próximos dela, irem viver lá, porque quem faz isto é pior que um assassino.

Um que vê tudo. ${ }^{6}$

Ao propor um circuito de comunicação como instrumento de análise para a história dos impressos, Robert Darnton adverte que, entre os elementos dessa rede formada por editores, livreiros, gráficos, entre outros agentes, seriam os leitores as personagens mais esquivas. Afinal, de acordo com o historiador, "a leitura continua a ser misteriosa" (DARNTON, 2010, p. 144). No entanto, os Autos Crimes de Exibição de Autógrafo julgados em Bragança e Campinas revelam leitores empíricos, na imensa maioria das vezes enfurecidos com o que liam. Nesse caso, poderíamos até ouvir as folhas do Diário de Campinas sendo amassadas pelas mãos de um leitor que se sentiu insultado ao ler o jornal pela manhã.

Mas não sabemos se Antonio Rodrigues Barbosa, nosso leitor empírico, expulsou ou não seus sogros idosos, conforme narrava a notícia. O fato é que ele se identificou como sendo uma das "biscas que mereciam ter a figura de tigres" e moveu uma ação contra Antonio Duarte de Moraes Sarmento, editor-proprietário do Diário de Campinas, pedindo a cabeça, ou melhor, o autógrafo daquele que se escondia por detrás do pseudônimo "Um que vê tudo".

6 COMUNICADO: Misericórdia. Diário de Campinas, Campinas, 19 jul. 1876, p. 3.

7 CMU TRIBUNAL DE JUSTIÇA DE CAMPINAS, Campinas. BARBOZA, Antonio Rodrigues. Exibição de autógrafo. Réu: Antonio Duarte Moraes Sarmento, 1876. Ofício 1, cx. 225, processo n. 4.588 . 
No dia seguinte à publicação da nota, a petição redigida pelo advogado de Antonio Rodrigues Barbosa era clara nessa direção: "o suplicante tem fundada suspeita que tal publicação se refere a si visto como seu sogro e sogra saíram de sua casa (isto é, livremente, bem entendido)", logo ele "requer a Vossa Senhoria se digne mandar intimar o redator da referida folha (...) para vir a primeira audiência pública exibir o autógrafo do autor de tal publicação a fim de, a vista dele, o suplicante proceder como for de lei". ${ }^{8}$ A audiência ocorreu no dia 22 de julho. Porém, Moraes Sarmento não apresentou o autógrafo argumentando "que segundo lhe declarou a pessoa que fez publicar ao artigo as alusões nele contidas não se inferem a pessoa do suplicante". ${ }^{9}$ Conforme previa a lei, o editor-proprietário do Diário de Campinas chamou para si a responsabilidade legal pelo artigo, sabe-se lá com a finalidade de proteger o verdadeiro autor.

Analisando a série em seu conjunto, sabemos que, a exemplo da Antonio Rodrigues Barbosa, o intervalo de tempo entre a publicação do texto considerado injurioso, sua leitura e o início de uma ação judicial era relativamente curto. Assim, 27 dos 48 processos tiveram início nos primeiros cinco dias após o aparecimento do artigo na imprensa, sendo que 11 deles foram movidos no mesmo dia da publicação. A maioria dos leitores ultrajados não perdia tempo.

Assim, nos primeiros dias de maio de 1901, correu a notícia de que um rapaz caíra morto na estrada de Valinhos. O médico da polícia foi ao local e, de fato, atestou o óbito causado por uma "comoção cerebral". Mas, no cemitério, revolveram colocar um espelho sobre os lábios do cadáver e, para espanto geral, constatou-se que ele respirava. A notícia anônima apareceu no jornal Comércio de Campinas que, além de veiculá-la, cobrava diligências do delegado sobre o caso. Porém,

8 CMU TRIBUNAL DE JUSTIÇA DE CAMPINAS, Campinas. BARBOZA, Antonio Rodrigues. Exibição de autógrafo. Réu: Antonio Duarte Moraes Sarmento, 1876. Ofício 1, cx. 225, processo n. 4.588 , fls. $3-3 \mathrm{v}$.

9 CMU TRIBUNAL DE JUSTIÇA DE CAMPINAS, Campinas. BARBOZA, Antonio Rodrigues. Exibição de autógrafo. Réu: Antonio Duarte Moraes Sarmento, 1876. Ofício 1, cx. 225, processo n. 4.588 , fls. 2 . 
o Dr. Eufrásio da Cunha, o médico, viu sua reputação abalada com o artigo e, no mesmo dia da publicação, solicitou a intimação do editor jornal para que ele apresentasse em juízo o autógrafo e a responsabilidade pelo texto anônimo. Com efeito, ficamos sabendo que foi José Pena o autor do texto. ${ }^{10}$

A grande maioria dos textos levados aos tribunais foram publicados na seção paga dos jornais, ou "seção ineditorial" conforme referido em alguns processos. A depender do veículo de imprensa, essa seção era chamada de "A pedidos", "Tribuna livre", "Seção livre" ou "Seção particular". Entre os artigos processados, $54 \%$ foram publicados precisamente nessa região bem delimitada da topografia dos jornais a qual, por suas características, volta e meia causava problemas legais aos proprietários, editores e redatores das folhas.

Por ser paga, paradoxalmente uma fonte de renda para os jornais, era na seção ineditorial que se concentravam a maioria dos textos anônimos ou assinados por pseudônimos e iniciais, tais como "D. M. J. da S", "Um imparcial", "Mosqueton", "O Justo", "Muitos republicanos", entre outros. Por conseguinte, a única maneira de um editor ou redator de jornal se eximir da culpa por um texto injurioso lá publicado era revelar em juízo o autógrafo e o documento de responsabilidade do autor escondido nesses e outros criptônimos.

Por exemplo, na edição de 9 de abril de 1881 da Gazeta de Campinas apareceu, na "Seção particular", um artigo intitulado "J. Gabriel”. Assinado por "Um eleitor" e empregando um tom jocoso, o texto exigia explicações daquele que estava por lançar-se candidato pelo Partido Conservador da cidade de Amparo. O fato de ter sido chamado de "protagonista de comédia” irritou o Dr. João Gabriel de Moraes Navarro que acabou por identificar-se com o "J. Gabriel" do título do artigo. No mesmo dia da publicação do artigo, Dr. João Gabriel solicitou ao juiz

10 CMU TRIBUNAL DE JUSTIÇA DE CAMPINAS, Campinas. CUNHA, Eufrásio. Exibição de autógrafo. Réu: Henrique de Barcellos, 1901. Ofício 4, cx. 241, processo n. 5854. 
que o editor da Gazeta de Campinas, Carlos Ferreira, apresentasse em audiência o autógrafo e o documento de responsabilidade. O sujeito indeterminado "Um eleitor" era, na verdade, o Dr. Ricardo Guimarães Duarte, "e por ser reconhecida a legalidade da mesma responsabilidade, declarou o juiz livre da responsabilidade o mesmo editor". ${ }^{11}$

O número de textos anônimos processados nos Autos Crimes de Exibição de Autógrafos ultrapassava os demais. Entre os 48 processos analisados, $44 \%$ referiam-se a artigos anônimos, $33 \%$ a textos assinados e 23\% empregaram pseudônimos. Não por acaso, Marcelo de Ipanema defendia que o anonimato, regulamentado por lei e revogado somente na República, foi a "velha e terrível árvore daninha da imprensa do Império" (IPANEMA, 1949a, p. 87-89). Porém, deve-se ressaltar que a assinatura do autor estampada no artigo impresso não isentava os editores e proprietários dos jornais de um eventual processo de exibição de autógrafo.

Entre esses casos, havia episódios intrigantes que revelam que o autor do texto publicado pode não tê-lo escrito literalmente, conforme denunciava a caligrafia sofrida no termo de responsabilidade. Ao menos foi assim com João Batista de Moura que publicou na "Seção Livre" do Diário de Campinas, de 10 de novembro de 1899, um artigo em que acusava José do Valle de "mau pagador, porém enérgico cobrador". ${ }^{12}$ O documento de reponsabilidade assinado por João Batista no dia anterior à publicação permite-nos inferir, com boa dose de certeza, que ele não escreveu nem o artigo, nem o termo de responsabilidade, conforme podemos observar na figura 2 .

11 CMU TRIBUNAL DE JUSTIÇA DE CAMPINAS, Campinas. NAVARRO, João Gabriel M. Exibição de autógrafo. Réu: Gazeta de Campinas, 1881. Ofício 2, cx. 46, processo n. 0498.

12 CMU TRIBUNAL DE JUSTIÇA DE CAMPINAS, Campinas. VALLE, José. Exibição de autógrafo. Réu: Diário de Campinas, 1899. Ofício 2, cx. 46, processo n. 0502. 
Figura 2: Documento de responsabilidade assinado por João Batista de Moura a 9 de novembro de 1899

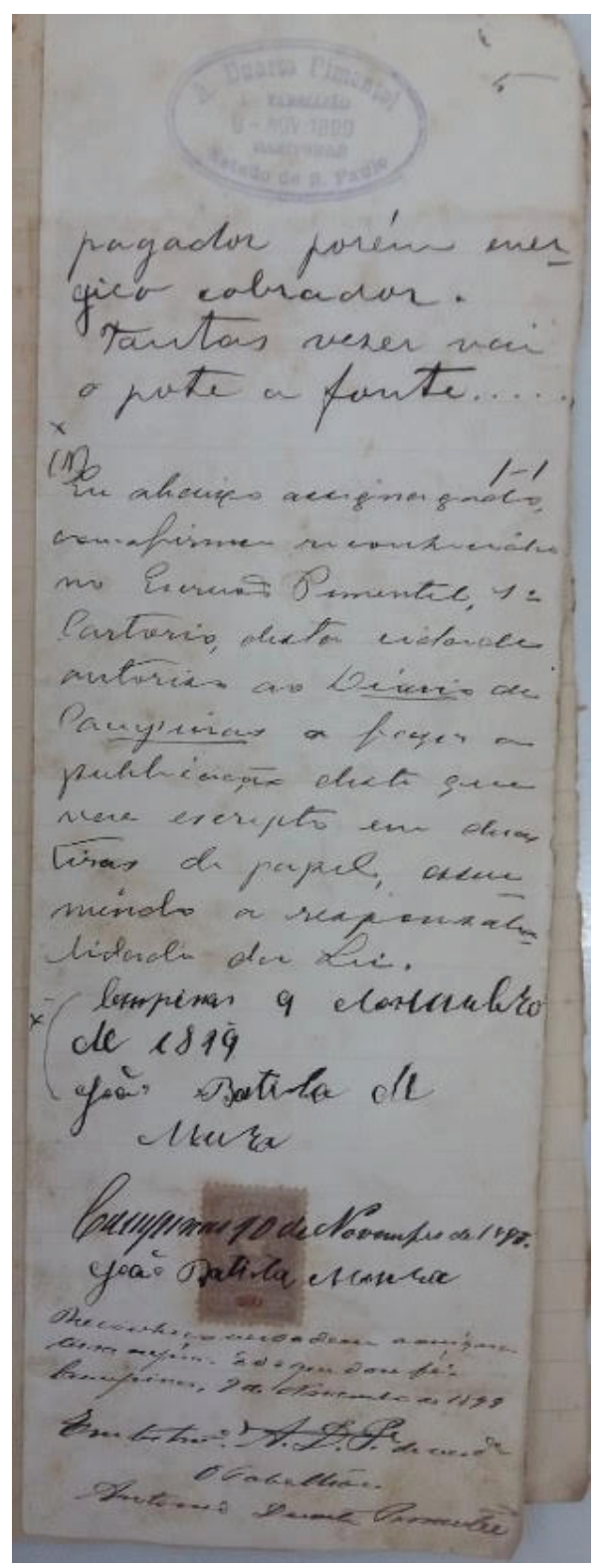

Fonte: CMU TRIBUNAL DE JUSTIÇA DE CAMPINAS, Campinas. VALLE, José. Exibição de autógrafo. Réu: Diário de Campinas, 1899. Ofício 2, cx. 46, processo n. 0502. 
Caso semelhante ao de Manuel Cândido da Silva, cuja esposa havia sido denunciada por um suposto infanticídio, em meados em 1881. Segundo a acusação, que logo provou-se infundada, a mulher de Manuel Cândido teria dado à luz e atirado a criança em um poço. Mas os médicos que a examinaram não descobriram vestígio de gravidez ou parto e, uma vez esvaziado, somente os restos de um galo afogado haviam sido encontrados no referido poço. Ainda assim o delegado levou a denúncia à sério, insistindo que mulher de Manuel Cândido assassinara o próprio filho. Manuel Candido então publicou um artigo assinado no Diário de Campinas de 16 de julho daquele ano com o título "O delegado parteiro". Sem disfarçar sua indignação com os abusos da autoridade, o artigo fazia troça: "Parece que o delegado de Campinas é prático em partos, abortos e supressões de crianças? Se não é parece". Injuriado com texto, o delegado, Comendador José Reggio Nóbrega, exigiu e obteve em juízo a responsabilidade assinada a rogo em nome de Manuel Cândido que, ainda que seguramente iletrado, não ignorava a força do tribunal tipográfico, para empregarmos a expressão utilizada por Jeanne Marie DeLombard (2007), ao qual recorria. ${ }^{13}$

Outros autores simplesmente desistiam do emprego de pseudônimos e, quiçá num derradeiro ato de bravura, assinavam os textos pouco antes de enviá-los aos prelos. No dia 26 de novembro de 1927, apareceu na seção "Tribuna livre" do Diário do Povo um artigo fustigando o antigo delegado de polícia de Campinas, Dr. José Penteado. Assinado por A. Carvalho, o texto insinuava que o delegado havia sido um péssimo aluno na Faculdade de Direito de São Paulo e que, sob sua jurisdição, o Jardim Chapadão convertera-se em uma verdadeira Monte Carlo, em referência certeira ao jogo ilegal que grassava na região. $\mathrm{O}$ ex-delegado peticionou a intimação do diretor-proprietário do Diário do Povo, Antonio Franco Cardoso, que apresentou o autógrafo e responsabilidade. O que chama a atenção, como demonstra a figura 3, é que o artigo

13 CMU TRIBUNAL DE JUSTIÇA DE CAMPINAS, Campinas. NÓBREGA, José Reggio. Exibição de autógrafo. Réu: Antônio Duarte Moraes Sarmento, 1881. Ofício 1, cx. 250, processo n. 05001. 
estava prestes a ser impresso com o pseudônimo "Um justiceiro", o qual foi riscado para que o autor, Arsênio de Carvalho, assumisse a autoria.

Figura 3: Original e documento de responsabilidade assinado por Arsênio de Carvalho a 25 de novembro de 1927

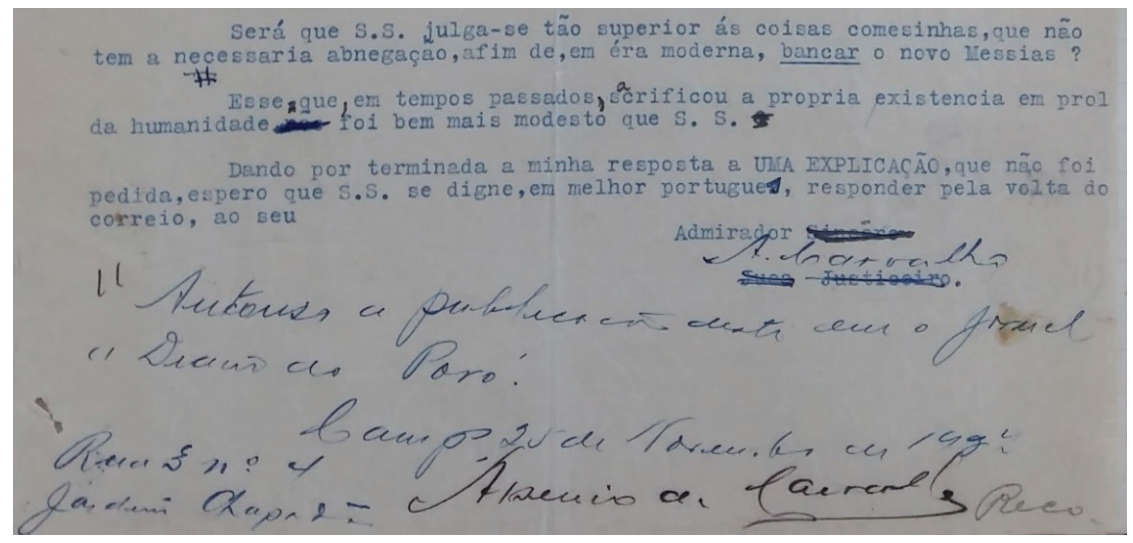

Fonte: CMU TRIBUNAL DE JUSTIÇA DE CAMPINAS, Campinas. PENTEADO, José. Exibição de autógrafo. Réu: Diretor Proprietário do Diário do Povo, 1927. Ofício 1, cx. 596, processo n. 1.1299 .

Mas, às vezes, era a verve dos autores que enganava. No dia 23 de janeiro de 1859, apareceu no Aurora Campineira um artigo anônimo acusando o Dr. Bernardino José de Campos de deflorar uma órfã de 12 anos. Erudito, o texto fazia referências a Nero que, a despeito das atrocidades que cometera na Antiguidade, ficaria aterrorizado com o crime. Na medida em que a justiça, imersa até o pescoço "no lodaçal do vergonhoso patronato", dava mostras de favorecimento ao suposto réu, o autor recorria ao tribunal da opinião pública com o objetivo de atar “o criminoso no pelourinho da imprensa”. Parecia até cousa de bacharel formado, ou por se formar, em São Paulo. Mas não era. O Dr. Bernardino de Campos peticionou ao juiz para que os impressores do jornal, os irmãos Siqueira e Silva, apresentassem o autógrafo do artigo. $\mathrm{Na}$ audiência, revelou-se que o autor era João Francisco de Souza, um carpinteiro de aproximadamente 17 anos. A dificuldade em se comprovar 
sua idade acabou por inocentá-lo. Afinal, o rapaz "não esta[va] no gozo dos seus direitos políticos". Com efeito, os irmãos Siqueira e Silva foram imputados responsáveis pelas injúrias e calúnias publicadas no jornal que editavam e imprimiam. ${ }^{14}$

\section{"SENTINDO-SE INJURIADO EM SUA HORA": OS TEMAS DOS ARTIGOS PROCESSADOS}

Como foi possível observar nos casos analisados no tópico anterior, a temática dos artigos imputados injuriosos variava. Em uma tentativa de classificação, podemos arriscar agrupá-los em torno de alguns assuntos, como Comércio, Honra, Municipalidade, Polícia, Política e Religião. Alguns temas prevaleceram sobre os outros, a exemplo da Honra, Comércio e Polícia.

Como tem demonstrado a historiografia que se debruçou sobre as injúrias verbais, sobretudo na Inglaterra dos séculos XVI ao XIX, a moral sexual foi tema nuclear na construção e aniquilamento da reputação dos indivíduos, principalmente das mulheres, perante a opinião pública (SHOEMAKER, 2000; GOWING, 1996; CAPP, 2003; WADDAMS, 2000). Com efeito, no tema Honra agrupam-se processos semelhantes ao movido pelo professor de piano João do Amaral contra A Ronca, semanário que circulou em Campinas no início da década de 1920. Duas notas publicadas no seminário nas edições de 25 de setembro e $1^{\circ}$ de outubro de 1921 enfureceram o músico. Na primeira, lia-se que "o maestrinho João do Amaral foi visto no cemitério, em companhia de duas mulheres cometendo atos escandalosos perante as catacumbas. Pobre mocidade! Está toda perdida!". A segunda nota, por sua vez, dizia que o "maestrinho João do Amaral quis cobrir de flores o escândalo que cometeu no cemitério em companhia de duas mulheres. Mas a lembrança vem tarde.... Os grifos originais sugerem que se tratava de prostitutas.

14 CMU TRIBUNAL DE JUSTIÇA DE CAMPINAS, Campinas. CAMPOS, Bernardino José de. Exibição de autógrafo. Réu: João Francisco de Souza, 1859. Ofício 1, cx. 154, processo n. 03252. 
Portanto, temendo por sua reputação, João do Amaral requereu a citação do diretor de A Ronca, Garibaldi Carpino, para apresentar o autógrafo da notícia. Porém, Carpino não compareceu à audiência. ${ }^{15}$

A única ação envolvendo uma leitora foi a movida por D. Salustiana Correa Pompeu contra o jornal $A$ Voz do Povo, de Campinas, em abril de 1928. Ainda que ela não tenha sido diretamente mencionada, o que torna difícil compreendermos o caso em sua totalidade, o artigo intitulado "Ladrões de Honra" levava ao tribunal tipográfico os acusados do defloramento de três órfãs, bem como os chauffeurs de praça habituados a seduzir moças e senhoras. Na audiência, o redator da Voz do Povo, Joaquim de Almeida Petta, assumiu a responsabilidade legal pelo artigo. ${ }^{16}$

No tema Comércio foram agrupados processos que versavam sobre atividades comerciais e econômicas, como as temidas cobranças de dívidas pela imprensa. Ao estudar os insultos verbais processados em Maryland no século XVII, Mary Berth Norton destacou o corte de gênero presente nos casos analisados. Naquele contexto, segundo a historiadora, se as mulheres se afligiam com acusações de promiscuidade sexual, os homens preocupavam-se muito mais com insultos que atacavam sua honestidade e confiabilidade nos negócios (NORTON, 1987, p. 3-39).

Padrão semelhantes pode ter se repetido nos Autos Crimes de Exibição de Autógrafo julgados em Bragança e Campinas. Se o número de mulheres é diminuto, apenas uma leitora em 48 processos, o número de leitores preocupados com os seus negócios é expressivo. Assim, na "Seção Livre" do jornal Comércio de Campinas, de 9 de dezembro de 1914, apareceu um artigo assinado por "Um morador do Taquaral". O texto tratava do mau procedimento de um fiscal da prefeitura que "enchendo o bandulho no botequim do sírio Miguel Elia, deixa-o ficar

15 CMU TRIBUNAL DE JUSTIÇA DE CAMPINAS, Campinas. AMARAL, João. Exibição de autógrafo, 1921. Ofício 3, cx. 50, processo n. 00722.

16 CMU TRIBUNAL DE JUSTIÇA DE CAMPINAS, Campinas. POMPEU, Salustiana C. Exibição de autógrafo. Réu: Joaquim A. Petta, 1928. Ofício 1, cx. 499, processo n. 08865. 
muito frescamente sem pagar os meses de licença que deve a prefeitura”. Nenhum fiscal se manifestou sobre o artigo, porém o sírio Miguel Elia queria saber quem o caluniava pela imprensa. Por conseguinte, o dono do botequim peticionou ao juiz que o gerente do Comércio de Campinas apresentasse em juízo o autógrafo e a responsabilidade pelo artigo. ${ }^{17}$

Outro grupo temático representativo referia-se à atuação da polícia, sobretudo os casos envolvendo artigos jornalísticos que denunciavam os desmandos e exageros cometidos pelos delegados. $\mathrm{O}$ caso de Manuel Cândido da Silva, marido de uma suposta infanticida, tratado acima, ilustra bem esse tipo de processo. Porém, havia os artigos imputados injuriosos também por cobrarem ação das autoridades policiais. Por exemplo, é possível imaginar os leitores acompanhando com avidez a série publicada no Correio de Campinas, entre janeiro e abril de 1886. Segundo ela, o jovem professor Antonio Custódio Soares teria sido espancado, morto, esquartejado e enterrado em sacos na fazenda do Manuel de Siqueira Freire, em Amparo. Porém, se por um lado até os escravos foram testemunhas do crime, por outro, houve quem dissesse que o professor estava são e salvo ministrando suas aulas na cidade. Mas enquanto o Correio de Campinas pedia explicações à polícia, o fazendeiro constituiu advogado e solicitou ao juiz o autógrafo e responsabilidade pelos artigos, os quais ele não conseguiu. ${ }^{18}$

Por fim, sem mais nos alongarmos nos estudos de caso, havia o grupo de artigos publicados na imprensa e processados por fustigarem padres, políticos, juízes e funcionários públicos relapsos. Por exemplo, no tema Religião está o padre José Joaquim de Souza e Oliveira, vigário da Paróquia de Nossa Conceição de Campinas que, em uma série de textos publicados no Constitucional em setembro de 1875, era alcunhado o vergalho e acusado de negociar escravos, constantemente

17 CMU TRIBUNAL DE JUSTIÇA DE CAMPINAS, Campinas. ELIAS, Miguel. Exibição de autógrafo. Réu: Comércio de Campinas (Abílio Álvaro Miller), 1914. Ofício 2, cx. 46, processo n. 0507.

18 CMU TRIBUNAL DE JUSTIÇA DE CAMPINAS, Campinas. FREIRE, Manuel O. Siqueira. Exibição de autógrafo. Réu: Correio de Campinas, 1886. Ofício 2, cx. 46, processo n. 0501. 
metendo o nariz aonde não devia. ${ }^{19}$ Já no tema Municipalidade, encontra-se o processo movido contra o redator do Comércio de Campinas em virtude das duas cartas que Albano Rodrigues Serra publicou denunciando os abusos cometidos pelo fiscal geral da Prefeitura, Benedito Claudino Gomes da Graça, em julho de 1919. ${ }^{20}$

\section{O DECLÍNIO DAS EXIBIÇÕES DE AUTÓGRAFO}

No dia 28 de novembro de 1935, o prefeito municipal de Campinas, José Pires Neto, "tendo sido injuriado em um artigo editado pelo Diário do Povo desta cidade, em data de ontem, na 'Tribuna Livre", requereu ao juiz que o editor-proprietário do jornal, Antônio Franco Cardoso, fosse intimado para comparecer à primeira audiência a fim de exibir o autógrafo do artigo. Cinco dias depois, Antônio Franco Cardoso compareceu em presença do juiz acompanhado por seu advogado e se negou a exibir o documento:

Porque a lei de imprensa suprimiu esse meio de saber-se qual o autor da publicação. A responsabilidade não é mais sucessiva, como pensa erradamente o requerente da exibição. Ao contrário, tal responsabilidade é precisa e determinada, em se tratando de imprensa periódica. O diretor ou redator principal é considerado autor de todos os escritos não assinados da parte editorial ou da redação. O gerente é considerado autor de todos os escritos não assinados da parte ineditorial. ${ }^{21}$

19 CMU TRIBUNAL DE JUSTIÇA DE CAMPINAS, Campinas. OLIVEIRA, José Joaquim de Souza. Exibição de autógrafo. Réu: Francisco Theodoro Siqueira Silva, 1875. Ofício 3, cx. 49, processo n. 00715 .

20 CMU TRIBUNAL DE JUSTIÇA DE CAMPINAS, Campinas. GRAÇA, Benedito C. Gomes. Exibição de autógrafo. Réu: Comércio de Campinas, 1919. Ofício 4, cx. 23, processo n. 0345.

21 CMU TRIBUNAL DE JUSTIÇA DE CAMPINAS, Campinas. NETO, José Pires. Exibição de autógrafo. Réu: Diário do Povo, 1935. Ofício 3, cx. 50, processo n. 00724. 
O prefeito acabou por desistir da ação. No entanto, interessa-nos o Decreto n. 24.776 de 14 de julho de 1934 citado nos autos, que, conforme argumentava o editor-proprietário do Diário do Povo, extinguia as exibições de autógrafo em juízo tal e qual elas eram feitas desde os tempos regenciais. Em linhas gerais, a lei de imprensa promulgada por Getúlio Vargas não alterava substancialmente a responsabilidade sucessiva. Assim, continuavam criminalmente responsáveis pelos abusos da liberdade de imprensa em primeiro lugar os autores, seguidos dos editores e, por fim, dos donos das oficinas de impressão. Porém, além de dedicar um capítulo especial à matrícula de jornais e oficinas impressoras, a lei passou a regular as responsabilidades a partir da topografia dos jornais, isto é, fazendo distinção entre as diferentes seções de uma folha e seus respectivos responsáveis legais, ${ }^{22}$ como bem explicava o editor Antonio Franco Cardoso.

Contudo, bem antes já é possível observar na série de processos analisados que as exibições de autógrafos paulatinamente tornavam-se ineficazes na identificação dos autores de textos injuriosos veiculados na imprensa. A princípio, dois fatores explicariam uma mudança que, de certo modo, foi ratificada no decreto assinado por Vargas, em 1934. Embora a pesquisa precise avançar nessa direção, nas últimas décadas do oitocentos assiste-se ao processo crescente de transformação dos jornais em empresas geridas por sociedades e associações. Por outro lado, também é marcante a ação dos editores dos jornais que simplesmente se negavam a exibir os autógrafos nas audiências.

O caso do professor João Brem versus o Comércio de Campinas pode bem elucidar a primeira hipótese. No dia 18 de junho de 1902, apareceu naquele jornal uma correspondência narrando como o professor, de repente, arvorou-se em chefe político no Arraial de Souzas. O artigo censurava os métodos por ele empregados para angariar votos, como as subscrições para iluminação pública e os reparos nas ruas. João Brem não gostou do que leu e processou o editor do Comércio de Campinas,

22 BRASIL. Decreto n. 24.776 de 14 de julho de 1934. Regula a liberdade de imprensa e dá providências. Rio de Janeiro: Diário Oficial da União, 14 jul. 1934. 
Henrique de Barcellos. Na audiência, o editor negou-se a apresentar o autógrafo, alegando não ser o responsável pelo jornal, o qual seria propriedade de uma associação. Imediatamente, o advogado do professor contra-argumentou: "A associação do Comércio de Campinas é uma ficção e como tal o oficial de justiça, ainda quando a procurasse durante muito tempo não a encontraria”. O impasse se encerrou apenas quando José Rocha, um "noticiarista do jornal Comércio de Campinas e como tal legítimo possuidor do autógrafo" apresentou-o em juízo. ${ }^{23}$

Em Campinas, o registro camarário dos jornais e periódicos era feito desde o século XIX, seguindo disposições do Código Criminal de 1830. Ainda que indiretamente, o artigo 303 do Código, que instituiu o registro, de certo modo também regulava a responsabilidade legal de impressores e redatores. Ora, por intermédio dos livros das Câmaras, eles podiam ser facilmente identificados. Assim, por exemplo, no dia 10 de abril de 1858, Silva e Irmão declaram perante o presidente e demais membros da Câmara Municipal de Campinas que haviam estabelecido uma oficina tipográfica da Rua do Pórtico, n. 17 e que nela começariam a imprimir a Aurora Campineira. ${ }^{24}$

A partir de 1919, entretanto, a responsabilidade legal pelos jornais e periódicos passou a ser o cerne dos registros camarários. Daquela data até 1932, foram registrados 37 termos de reponsabilidade pela publicação de jornais e periódicos na Câmara Municipal de Campinas. Em 17 deles, os proprietários dos impressos declaram-se responsáveis legais. As folhas diárias, a exemplo do Comércio de Campinas, jornal de propriedade do Major Manuel Francisco Mendes, preferencialmente registravam o termo de responsabilidade em nome de seus redatores. E o mesmo se dava com os jornais e periódicos publicados por associações, a exemplo do Campinas-Jornal da Associação dos Cirurgiões Dentistas de Campinas. Nesse caso, o termo de responsabilidade,

23 CMU TRIBUNAL DE JUSTIÇA DE CAMPINAS, Campinas. BREM, João. Exibição de autó_ grafo. Réu: Henrique Barcellos, 1902. Ofício 1, cx. 368, processo n. 6.809.

24 ARQUIVO DA CÂMARA MUNICIPAL DE CAMPINAS, Campinas. Imprensa Campineira, 1858-1859. L. 150, fo 2-2v. 
lavrado em janeiro de 1928, fora registrado em nome do redator, o cirurgião-dentista Pedro Luís Bastos da Silva. Até o Mensageiro Cristão, periódico da Diocese de Campinas, estava registrado em nome de seu redator-chefe, o Pe. Miguel Andery. ${ }^{25}$

Contudo, alguns editores e redatores começaram a se negar a exibir os autógrafos em juízo alegando que os textos imputados injuriosos eram de autoria da redação. Por exemplo, as notícias de Itatiba publicadas no Diário de Campinas de 11 de dezembro de 1888 davam conta do êxito dos alunos daquela cidade nos exames das escolas públicas, assim como das pessoas que foram a Jundiaí a fim de assistirem a uma concorrida conferência republicana e dos sopapos trocados entre o italiano Francisco Cosenza e o fazendeiro Eleutério Alves Cardoso. Dois dias antes, o fazendeiro teria dito algumas "palavras ofensivas à colônia italiana”, razão pela qual o imigrante lançou-se sobre ele dandolhe algumas bofetadas. Eleutério Cardoso não gostou de ver o incidente estampado no jornal e, portanto, demandou pela exibição do autógrafo. Mas o redator do Diário de Campinas negou-se a apresentar os documentos, pois, segundo ele, tratava-se um "escrito filial feito pela redação do jornal" ${ }^{26}$

De modo semelhante, no dia 21 de outubro de 1898, apareceu no jornal Cidade de Campinas um artigo intitulado "Abuso inqualificável" que clamava pela atenção do delegado de polícia contra a campanha eleitoral imprópria feita pelo coletor de rendas do munícipio, Pedro Dias de Almeida. Sentindo-se caluniado e injuriado, o coletor requereu a exibição do autógrafo do artigo em juízo. Porém, Alberto de Faria, editor do Cidade de Campinas, negou-se a apresentar o documento com os mesmos argumentos, pois "se tratava de matéria de redação". ${ }^{27}$

25 ARQUIVO MUNICIPAL DE CAMPINAS, Campinas. Termos de Responsabilidade para Publicação e Jornais e Periódicos em Campinas, 1919-1932. fo 1-19v.

26 CMU TRIBUNAL DE JUSTIÇA DE CAMPINAS, Campinas. CARDOSO, Eleutério Alvez. Exibição de autógrafo. Réu: Antonio Duarte Moraes Sarmento, 1888. Ofício 1, cx. 288, processo n. 05597.

27 CMU TRIBUNAL DE JUSTIÇA DE CAMPINAS, Campinas. EDITOR JORNAL CIDADE DE CAMPINAS. Exibição de autógrafo, 1898. Ofício 3, cx. 50, processo n. 718. 
Havia também os editores que, por sua conta e risco, colocavam em prática a legislação francesa de imprensa. Assim, na seção "Notícias do interior" do Comércio de Campinas de 27 de julho de 1915, apareceu um artigo do correspondente de Jaguary. A "carência de polícia" fazia que, vez por outra, o delegado daquela cidade solicitasse auxílio de "curiosos" nas diligências policiais os quais, a exemplo de Alberto Almeida e Constantino Barreto, a pretexto de ajudarem andavam praticando brutalidades. Três dias depois, os curiosos citados no texto peticionaram no Tribunal de Campinas a exibição do autógrafo do artigo. Na audiência, o gerente do jornal alegou que o autor era o correspondente que, em novo artigo, havia se retratado. Citando o Droit de Réponse dos franceses, que regulava a retratação, o gerente argumentou que a responsabilidade do jornal estava salvaguardada. ${ }^{28}$

\section{ORALIDADE, CULTURA IMPRESSA E LIBERDADE DE EXPRESSÃO NO BRASIL: À GUISA DE CONCLUSÃo}

Em abril de 1800, a parda Antônia Mendes, proprietária de um sítio próximo à Vila Nova de Bragança, capaz de assinar com desenvoltura a procuração com a qual constituiu seu advogado, acusou formalmente Rosa Mendes e sua escrava Bernarda de caluniá-la pela vizinhança. Rosa perdera um lenço no caminho das terras de Antônia, a quem passou a acusar aos quatro ventos de tê-lo encontrado e furtado, com isso infamando "o crédito da autora publicamente e perante a justiça desta Vila”. ${ }^{29}$ A viúva Anna Leme, por sua vez, encontrava-se no monjolo de sua propriedade "mansa e pacificamente cuidando em o serviço manual de sua casa", quando foi abordada por Lourenço Pires que a insultou, chamando-a, "com o devido respeito, de puta, de cadela", motivo pelo

28 CMU TRIBUNAL DE JUSTIÇA DE CAMPINAS, Campinas. BARRETO; Constantino; ALMEIDA, Alberto. Exibição de autógrafo. Réu: Comércio Campinas, 1915. Ofício 3, cx. 50, processo n. 00719.

29 CDAPH-USF, Bragança Paulista. MENDES, Antônia. Libelo de injúria. Rés: Rosa Mendes e sua escrava Bernarda, 1800. Cx. 3, pasta 9. 
qual foi processado. ${ }^{30}$ Já em dezembro de 1842, o Padre Manuel Joaquim Gonçalves de Andrade igualmente processou Policarpo Gonçalves de Godoi que, segundo o reverendo, caluniava-o pelas ruas de Bragança dizendo que ele mantinha relações ilícitas com uma mulher "que, para poder viver com decência, se sujeita a prestar aqueles serviços próprios do seu préstimo a quem deles precisa e lhes sabe recompensar, digo, sabe retribuir" ${ }^{31}$

Processos por injúrias verbais semelhantes aos movidos por Antônia Mendes, Anna Leme e pelo Padre Manuel são fascinantes. Por intermédio dessas fontes é possível acessar as experiências de pessoas comuns em suas relações conflituosas com membros de suas comunidades. Ao analisar casos semelhantes julgados em tribunais eclesiásticos ingleses na primeira metade do século XIX, Stephen M. Waddams (2000) constatou que grande parte dos processos eram movidos por mulheres que viviam na mesma vizinhança. Entre os homens, descavam-se justamente os processos movidos por clérigos difamados por suposta má conduta sexual. ${ }^{32}$

Contudo, na Era Moderna, diante da vulgarização das prensas de tipos móveis, ao lado dos insultos verbais, as calúnias impressas adquiriram cada vez mais relevância nos tribunais ingleses. De acordo com Robert B. Shoemaker (2000, p. 122), "a difamação política ocorria frequentemente na imprensa, veículo que passou a ser percebido no

30 CDAPH-USF, Bragança Paulista. LEME, Anna. Injúria verbal. Réu: Lourenço Pires Cardoso, 1810. Cx. 15, pasta 15 .

31 CDAPH-USF, Bragança Paulista. ANDRADE, Rev. Manuel Joaquim Gonçalves de. Sumário de crime de injúria. Réu: Policarpo Gonçalves de Godoi, 1842. Cx. 51, pasta 14.

32 De um modo geral, a historiografia tem se baseado em processos de injúrias verbais para acessar o cotidiano, bem como as relações sociais tecidas pelos indivíduos em diferentes contextos espaço-temporais. Sublinhe-se que a historiografia anglo-americana nesse tema é vasta. Assim, embora Robert B. Shoemaker (2000) tenha constatado mudanças quantitativas e qualitativas substâncias nos casos julgados nos tribunais britânicos no início da Era Moderna, Laura Gowing (1996) indicou o papel central da sexualidade na construção da reputação feminina. Neste sentido, Bernard Capp (2003) baseou suas pesquisas em processos de calúnia na literatura popular para justamente mostrar a agência de mulheres de diferentes estratos sociais nos tribunais. 
decorrer do século XVIII como tendo um impacto muito mais poderoso sobre as reputações do que o insulto verbal". Para o autor, jornais e libelos redigidos em versos, manuscritos ou impressos, complementariam métodos orais de propagação de calúnias. A calúnia impressa, no entanto, passaria a ser considerada ainda mais grave na medida em que, além de envolver a premeditação do autor, infligia danos muito mais duradouros. Partindo da constatação de que a Inglaterra no período se caracterizava como uma sociedade em que as taxas de letramento eram extremamente baixas, Adam Fox (1994) argumenta que os libelos caluniosos se encontravam na encruzilhada entre oralidade, escrita, leitura e imprensa.

Este artigo analisou o impacto da expansão da malha tipográfica pelo interior de São Paulo a partir da segunda metade do século XIX, com vistas a compreender de que modo a imprensa transformou o cotidiano de homens e mulheres, ao passo que ela também sofria profundas transformações. O baixo índice de pessoas capazes de ler um jornal de modo algum inviabilizou o aumento progressivo das oficinas tipográficas e, em consequência, o avanço da imprensa na região. Na medida em que jornais e revistas começaram a integrar a vida das pessoas, letradas ou iletradas, a liberdade de imprensa também foi sendo moldada na intersecção histórica entre calúnias e injúrias orais e calúnias e injúrias impressas.

Parte essencial do liberalismo adotado pelos novos regimes constitucionais do século XIX, a liberdade de imprensa foi garantida e regulada por uma série de dispositivos legais. Contudo, como indicam as ações preparatórias que tinham por objetivo identificar os réus nos casos de excesso daquela prerrogativa, ela foi igualmente construída nos tribunais. Por conseguinte, a documentação judicial analisada nos revela os mecanismos de funcionamento da justiça brasileira no âmbito dos crimes de imprensa e da regulamentação da liberdade de expressão. Não obstante, os autos crimes de exibição de autógrafo também demonstram as transformações que o aparato legal elaborado para regular a imprensa concomitantemente sofria em virtude da ação dos atores sociais envolvidos nos processos, ou seja, leitores, jornalistas, redatores e proprietários de jornais. 
Em termos historiográficos, até o momento não localizei estudos sobre a imprensa no Brasil que empregassem processos criminais com o objetivo de compreender a historicidade da liberdade de expressão no país. Merecem destaque, no entanto, as compilações de leis de imprensa elaboradas por Marcello de Ipanema (1949a; 1949b e 1949c) e Antonio F. Costella (1970). A legislação de imprensa também recebeu alguma atenção nos estudos de Nelson Werneck Sodré (1999) e Isabel Lustosa (2000), sobressaindo-se na produção recente a dissertação de mestrado de Tassia Toffoli Nunes (2010) que analisou os debates parlamentares em torno da imprensa, entre 1820 e 1840.

Não obstante a centralidade da sedição e da apostasia previstas no Código Criminal de 1830 e nas demais leis e decretos promulgados no Brasil com intuito de regular a produção e circulação de impressos, eram a calúnia e a difamação que moviam as engrenagens do poder judiciário nos casos de crime de imprensa. Com efeito, diante do advento das novas tecnologias de reprodução da palavra impressa, os processos judiciais analisados revelam uma espécie de transposição da oralidade das ruas para as páginas de jornais e revistas. Entretanto, embora previstas em lei por aproximadamente um século e julgadas nos tribunais de Campinas e Bragança por cerca de setenta anos, o problema histórico suscitado pelos autos crimes de exibição de autógrafo não se encerrou em 1934. Em um texto recente, Clarissa Gross (2020) analisou a fragilidade da liberdade de expressão garantida no artigo $5^{\circ}$, parágrafo IV, da Constituição de 1988. Para a estudiosa do Direito, ainda são nos crimes contra a honra - nomeadamente a calúnia, difamação e injúria - que residem os principais entraves à liberdade de expressão no país. Ainda é em nome dela que, por exemplo, biografias foram recentemente censuradas no Brasil.

\section{Agradecimentos}

Pesquisa financiada pela Fundação de Amparo à Pesquisa do Estado de São Paulo - FAPESP (Processo n. 2018/08933-0). 


\section{REFERÊNCIAS BIBLIOGRÁFICAS}

ALMANACH para o ano de 1896 publicado pelo O Estado de S. Paulo. São Paulo: J. Filinto \& C., 1896.

CAPP, Bernard. When Gossip Meet: Women, Family, and Neighborhood in Early Modern England. New York: Clarendon Press, 2003.

COSTELLA, Antonio F. O Controle da informação no Brasil: evolução histórica da Legislação Brasileira de Imprensa. Petrópolis: Vozes, 1970.

DARNTON, Robert. O Beijo de Lamourette: mídia, cultura e comunicação. São Paulo: Companhia das Letras, 2010.

DELOMBARD, Jeanne Marie. Slavery on trial: Law, Abolicionism, and Print Culture. Chapel Hill: The University of North Caroline Press, 2007. DISCURSO recitado pelo Exmo. Presidente da Rafael Tobias de Aguiar no dia 7 de janeiro de 1841 por ocasião da abertura da Assembleia Legislativa da Província de São Paulo. São Paulo: Tipografia de Costa Silveira, 1841.

DISCURSO recitado pelo Exmo. Presidente José Carlos Pereira de Almeida Torres no dia 7 de janeiro de 1843 por ocasião da abertura da Assembleia Legislativa da Província de S. Paulo. São Paulo: Tipografia do Governo, 1843.

FOX, Adam. Ballads, Libels and Popular Ridicule in Jacobean England. Past \& Present, n. 145, p. 47-83, Nov. 1994.

FREITAS, Afonso A. de. O Primeiro centenário da fundação da Imprensa em São Paulo. Revista do Instituto Histórico e Geográfico de São Paulo, São Paulo, p. 7-42, 1928.

GANTÚS, Fausta. La Libertad de imprenta en el siglo XIX: vaivenes e tensiones de su regulación. História Mexicana, v. 69, n. 1, p. 93-114, 2019.

GODOI, Rodrigo Camargo de. Um Editor no Império: Francisco de Paula Brito (1809-1861). São Paulo: Edusp; Fapesp, 2016.

GOWING, Laura. Domestic Dangers: Women, Words and Sex in Early Modern London. New York: Clarendon Press, 1996.

GROSS, Clarissa. A Palavra em perigo. Quatro cinco um, São Paulo, n. 32, abr. 2020. 
IPANEMA, Marcelo de. Síntese da História da Legislação Luso-Brasileira de Imprensa. Rio de Janeiro: Aurora, 1949a.

IPANEMA, Marcelo de. Estudos de história de legislação de imprensa. Rio de Janeiro: Aurora, 1949b.

IPANEMA, Marcelo de. Livro das leis de imprensa de D. João. Rio de Janeiro: Aurora, 1949c.

LAPA, Alcides. A Imprensa em Bragança. In: MONTEIRO, Oscar (Org.). Almanak Histórico-literário do Estado de S. Paulo para o ano de 1897. São Paulo: Oscar Monteiro, (s. d.). p. 237-239.

LUNÉ, Antonio José Baptista de; FONSECA, Paulo Defino (Orgs.). Almanak da Província de São Paulo para o ano de 1873. São Paulo: Tipografia Americana, 1873.

LUSTOSA, Isabel. Insultos impressos: a guerra dos jornalistas na independência, 1821-1823. São Paulo: Companhia das Letras, 2000.

MARINHO, Joaquim Saldanha. Jurisdição criminal: Tribunal da Relação da Corte. Apelação Crime n. 153. Gazeta Jurídica, p. 464-481, 1875.

MILTON, John. Areopagítica: discurso pela liberdade de imprensa ao Parlamento da Inglaterra. Rio de Janeiro: Topbooks, 1999.

MOURA, Francisco Inácio Xavier de Assis (Org.). Almanach Administrativo, Comercial e Industrial da Província de São Paulo para o ano bissexto de 1884. São Paulo: Proprietário; Jorge Seckler e Cia., 1883.

NABUCO, Joaquim. Um Estadista do Império: Nabuco de Araújo, sua vida, suas opiniões, sua época. Rio de Janeiro; Paris: H. Garnier, 1897.

NORTON, Mary Beth. Gender and Defamation in Seventeenth-Century Maryland. The William and Mary Quarterly, v. 44, n. 1, p. 3-39, Jan. 1987. NUNES, Talissa Toffoli. Liberdade de imprensa no Império brasileiro: os debates parlamentares (1820-1840). Dissertação (Mestrado em História) - Universidade de São Paulo, São Paulo, 2010.

RELATÓRIO com que o Ilmo. Exmo. Sr. Dr. Josino do Nascimento Silva presidente da Província de S. Paulo abriu a Assembleia Legislativa Provincial no dia 16 de fevereiro de 1854. São Paulo: Tipografia 2 de Dezembro de Antonio Louzada Antunes, 1854. 
SEELAENDER, Airton Cerqueira Leite. Surgimento da ideia de liberdades essenciais relativas à informação: a Aeropagitica de Milton. Revista USP, v. 86, p. 190-211, 1991.

SHOEMAKER, Robert B. The Decline of Public Insult in London, 1660-1800. Past \& Present, n. 169, p. 97-131, Nov. 2000.

SODRÉ, Nelson Werneck. História da Imprensa no Brasil. Rio de Janeiro: Mauad, 1999.

THÉRENTY, Marie-Eve. Relojes blandos y periódicos locos: ritmos y imaginários del tempo cotidiano en el siglo XIX. In: SUÁREZ DE LA TORRE, Laura (Ed.). La Invención de la cultura mediática: prensa, literatura y sociedad en Francia en el siglo XIX. Mexico: Instituto Mora, 2013. p. 52-53.

WADDAMS, Stephen M. Sexual Slander in Nineteenth-Century England: Defamation in the Ecclesiastical Courts, 1815-1855. Toronto: University of Toronto Press, 2000.

ZELTSMAN, Corinna. Defining Responsibility: Printers, Politics, and the Law in Early Republican Mexico City. Hispanic American Historical Review, v. 2, n. 98, p. 189-222, 2018. 